\title{
Parental Factors as Determinants of Conduct Disorder among In-School Adolescents in Ibadan Metropolis, Nigeria
}

\section{Daniel Oluwasanmi Kumuyi ${ }^{1}$, Ebenezer Olutope Akinnawo', Aderonke A. Akintola1,

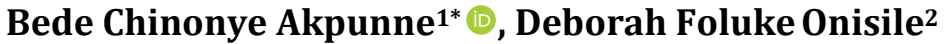

${ }^{1}$ Department of Behavioural Studies, Faculty of Social Sciences, Redeemer's University, Ede, Nigeria

${ }^{2}$ Department of Nursing Science, Faculty of Basic Medical Sciences, Redeemer's University, Ede, Nigeria

Email: *akpunneb@run.edu.ng

How to cite this paper: Kumuyi, D. O., Akinnawo, E. O., Akintola, A. A., Akpunne, B. C., \& Onisile, D. F. (2021). Parental Factors as Determinants of Conduct Disorder among In-School Adolescents in Ibadan Metropolis, Nigeria. Psychology, 12, 643-659.

https://doi.org/10.4236/psych.2021.124040

Received: March 5, 2021

Accepted: April 27, 2021

Published: April 30, 2021

Copyright $\odot 2021$ by author(s) and Scientific Research Publishing Inc. This work is licensed under the Creative Commons Attribution International License (CC BY 4.0).

http://creativecommons.org/licenses/by/4.0/

(c) $\underset{\mathrm{By}}{\mathrm{i}}$ Open Access

\begin{abstract}
This study was carried out to observe the link between parental factors and Conduct Disorder (CD) among Nigerian school adolescents. A cross-sectional survey research design was adopted for the study where multi-stage sampling techniques led to selecting 1006 participants (mean age $=15.4$ years) from six secondary schools in Ibadan, Oyo State, Southwestern Nigeria. Participants responded to Socioeconomic Status (SES) scale, the Parenting Styles Scale (PSS) and Frequency of Delinquent Behaviour Scaling Instrument (FDBSI). A high prevalence of $\mathrm{CD}$ was observed. We also observed that parenting styles significantly influenced conduct disorders. Responsive parenting is not a significant predictor of $\mathrm{CD}$, while control parenting significantly predicted $\mathrm{CD}$. Parental occupation significantly influenced $C D$, with formal occupation types having higher mean scores for both fathers and mothers. Finally, there was a significant influence of socioeconomic status on conduct disorder among the participants. Findings concluded that there is a high prevalence of conduct disorder. Authoritarian and uninvolved parents with formal occupation and families with higher socioeconomic status were conduct disorder determinants among adolescents.
\end{abstract}

\section{Keywords}

Parental Styles, Conduct Disorder, Adolescents, Nigeria

\section{Introduction}

Conduct disorder (CD) is a common and highly impairing psychological disorder that usually emerges in childhood or adolescence and is characterized by 
severe antisocial and aggressive behaviour (Fairchild et al., 2019). Aggression is part of human nature. The ability to defend oneself against verbal or physical attacks contributes to survival and adaptation. Aggressive behaviors, such as hitting, pushing, slapping, biting, kicking, spitting, and hair-pulling, are universal in young children (Tremblay, 2010).

Interactions with caregivers play essential roles in shaping children's behavioural repertoire towards more socially acceptable forms of defending their rights and expressing their wishes. However, some adolescents fail to follow this socialization path and frequently manifest aggressive and rule-breaking behaviour. These adolescents may fall within the categorical classification of disruptive behaviour disorder, the most severe of which is conduct disorder (Buitelaar et al., 2012).

Signs and Symptoms of conduct disorder include fights, bullying, use of a weapon to cause harm, stealing, forced sexual activity, deliberate fire setting, lying, running away overnight without returning for a lengthy period, and truancy (APA, 2013). CD sometimes progresses from oppositional defiant disorder, usually from age four to six years (APA, 2013). Adolescence corresponds to the period between the ages of 10 and 19 years and is often a critical phase in each person's life cycle because it marks a period of biological, social, and psychological transition between childhood and adulthood (WHO, 2016). The period is a time of strain and stress fraught with many problems. Thus, it is characterized by instability and susceptibility to the development of psychological distress, which may lead to engaging in delinquency to reduce or escape from the strain they are experiencing (Calado et al., 2017). Previous researchers also established that the "stress and storm" that adolescents go through make them experience mood disruptions, risky behaviour, and conflicts with parents (Feist, Feist, \& Roberts, 2013).

The antisocial behaviors often associated with conduct problems, such as vandalism, drug abuse, weapon carrying, alcohol abuse, rape, examination malpractices, school violence, bullying, cultism, truancy, school dropouts are on the increase in Nigerian cosmopolitan cities (Chiedu et al., 2015; Saheed, 2019). For professionals working with children and adolescents, $\mathrm{CD}$ and other disruptive behaviors serve as the most frequently observed mental health concerns (Baker, 2012). The global prevalence of conduct disorder ranged from $2 \%$ to $10 \%$ (American Psychiatric Association, 2013; Canino et al., 2010; Scott, 2007). In Nigeria, there is scarce literature on conduct disorder. However, some Nigerian studies reported a $14.5 \%$ - $15.8 \%$ CD prevalence rate among in-school adolescents (Frank-Briggs \& Alikor, 2008; Ojuope \& Ekundayo, 2020). More up-to-date information on CD's prevalence and aetiology are imperative to serve as baseline data for CD preventive strategies.

Among others, one theory with which we explain CD is the attachment theory (Bowlby, 1969). Attachment refers to an emotional bond with another person. According to DeKlyen and Speltz (2000), the attachment theory offers a unique framework in understanding the development of conduct disorder. The theory 
focuses on the impact of parent-child attachment in developing either a healthy, well-adjusted child or manifestation of psychopathology and behavioral problems (Bowlby, 1969; Hoeve, Dubas, Gerris, van der Laan, \& Smeenk, 2011).

The theory has proven to be a very promising framework for studying normal and abnormal development of an individual. Bowlby (1969) suggests that early relational experiences have great significance for later development. One of the major tenets he puts forward is that infants and young children need to develop a secure attachment with parents before launching out into unfamiliar situations. The child's attachment behaviour is later activated in especially uncomfortable and frightening situations. The crust of the attachment theory is on the importance of the availability and responsiveness of primary caregivers to an infant's needs and how these allow the child to develop a sense of security. Once an infant knows the primary caregiver is dependable, a secure base for exploration of the rest of the world is created in the child (Bowlby, 1982).

Research reveals that insecure attachment early in life increases psychopathology vulnerability and other negative impacts on behaviour in later childhood and throughout life (Young, Simpson, Griskevicius, Huelsnitz, \& Fleck, 2019; Mikulincer \& Shaver, 2012). Children diagnosed with conduct disorder, oppositional defiant disorder (ODD) and post-traumatic stress disorder (PTSD) often manifest attachment problems, possibly due to early abuse, neglect, or trauma (Hoeve, Dubas, Gerris, van der Laan, \& Smeenk, 2011). On the other hand, infants who are securely attached in childhood tend to have good self-esteem, strong romantic relationships, tend to be more independent, perform better in school, have successful social relationships, experience less depression and anxiety and the ability to self-disclose to others (Young et al., 2019). Factors such as parenting styles, parental occupation and social-economic status (SES) could impinge upon the availability and responsiveness of caregivers and impact upon the nature of attachment.

The family lays the psychological and social foundations in the overall development from childhood to adulthood. Adolescents from disadvantaged, dysfunctional, and chaotic home environments are more likely to develop conduct disorders (Busari \& Adejumobi, 2012). While the mother's significant role in this cannot be over-emphasized, studies on the father-child relationship suggest that the presence of a father in the home significantly influences a child's development (Yap, Fowler, Reavley, \& Jorm, 2015). Many studies have shown that parenting affects children's behavioural outcomes (Akinnawo, Akpunne, \& Olajide 2019; Farmer et al., 2016). Lewis et al. (2017) and Van der Ende et al. (2016) found that adolescents who lacked adequate parental supervision were more likely to engage in criminal activities.

Parenting is not a specific act but a complex activity that includes many specific behaviors that work individually and together to influence child outcomes. Parenting style captures normal variations in parents' attempts to control and socialize their children (Baumrind, 1991). Parenting styles were derived from 
two primary constructs: responsiveness and demandingness (Baumrind, 1991), and further categorized into a quadrant (indulgent/permissive, authoritarian, authoritative, and uninvolved/neglect) (Maccoby \& Martin, 1983). Verzello (2010) reported differing correlations between parenting styles and CD. Also, Hockenbury (2013) argues that the authoritative parenting style facilitates a healthy parent-child relationship.

The influence of parents' occupation on child psychopathology is unclear. Existing literature on this relationship adopts the socioeconomic perspective in which parental occupation is conceptualized, along with education and income, as a measure of Socio-Economic Status (SES). Chen and Paterson (2006) report a significant correlation between the adolescent manifestation of hostility, the parent's occupation, and family income. Studies suggest a link between low parental income and adverse mental health for children (APA, 2015; Chen, 2004; Propper \& Rigg, 2007). Similarly, Gureje et al. (2006) and Cronin et al. (2015) posited that low-income families are prone to higher stress levels with children predisposed to psychopathology than middle and high-income families.

Another perspective of interest is the influence of parents' occupational status on $\mathrm{CD}$. In a study on mothers who work versus those who do not, Heinrich (2014) affirms the negative influence of being employed on parenting viz.: providing the financial means to meet parenting obligations and reducing the time available to spend with family. Researchers reported that parenting accounts for more variance in externalizing behaviour in adolescence than any other factor (Crosswhite \& Kerpelman, 2009; Gavazzi, 2006; Simons et al., 2001; Dekovic \& Janssens, 2003).

Parenting adolescents can be challenging. Studies show significant links between ineffective parenting practices and the development or escalation of child conduct problems (Dodge et al., 2008; Kilgore et al., 2000; Smith \& Farrington, 2004). Nevertheless, gaps in this link exist in Nigerian studies, which necessitates this research project.

\section{Hypotheses}

1) Perceived parenting style (Authoritative, Authoritarian, Permissive, and Uninvolved) would significantly, jointly, and independently influence conduct disorder among in-school adolescents in Ibadan, Metropolis.

2) Adolescents whose parents have formal occupation would significantly score higher on conduct disorder than their counterparts whose parents have Informal occupation in Ibadan Metropolis.

3) Socioeconomic Status (SES) would significantly influence conduct disorder among in-school adolescents in Ibadan Metropolis.

\section{Methods and Material}

\subsection{Participants}

The study population is in-school secondary school adolescents in Ibadan Me- 
tropolis Oyo State Southwestern Nigeria. A total of one thousand and six (1006) adolescents selected from three junior secondary schools and three senior secondary schools participated in the study.

A cross-sectional survey design was employed in this study. In line with Bartlett et al. (2001) recommendation that $50 \%$ of the target population must be used for a study to be representative, a multi-stage sampling technique was employed in this study. The ballot technique was used to randomly select three out of the five Local Government Areas (LGAs) in the Ibadan metropolis. Schools in the Metropolis already existed in the stratified form in each local government as public and private. Next, a convenient sampling technique was employed in selecting only two public and private schools from each of the three LGAs. Finally, a systematic sampling technique was employed in selecting the adolescent that was willing to participate in the study. The breakdown of the samples by their schools include 211 students of Adesina College, 131 students from Anglican Grammar School, and 142 students from Bishop Philips Academy. Also, 109 participants were selected from IMG Grammar School, 317 from Oritamefa Baptist Junior and Secondary School, and 96 participants from St. Patrick Grammar School.

\subsection{Measures}

A battery of three instruments was further adapted and used as tools for data collection.

The Socioeconomic Status (SES) scale is a 20 items self-reported adolescents' declaration of their household structure and items. It was combined with parents' self-report of their monthly financial income and highest educational qualification for objective estimation and analysis of their socioeconomic status. Scale items were derived from a pool of household survey Questionnaire (OECD, 2008). It has a reliability coefficient of 0.82 . Examples of items in the scale are: "Source of Water Supply" "What type of roofing material is used in your house." A composite score was obtained, the highest being 42 . Scores below 20 are considered low, while scores above 35 are considered high.

The Parenting Styles Scale (PSS) by (Gafoor \& Abdha, 2014) is a-38 items scored on 5-Likert format ranging from 5 = "Very Right", 4 = "Mostly Right", $3=$ "Sometimes Right", 2 = "Sometimes Wrong", 1 = "Mostly Wrong". Examples of items in the scale are: "Points out my mistakes in the manner that I understand" and "Tries to frame my likes and dislikes" PSS has been found to have a validity coefficient of 0.80 for responsiveness and 0.76 for the control subscale, and a test-retest Cronbach Alpha for responsiveness is 0.81, and control had 0.83.

Frequency of Delinquent Behaviour Scaling Instrument (FDBSI) by (Dahlberg et al., 2005) is a 25 -item instrument with six subscale measures, vandalism, theft, physical aggression, truancy, and other school problems, disruptive behaviour, and status offence. Participants respond on a 5-point scale of "Never", "1 - 2 times", "3 - 6 times", "7 - 9 times" and "More than ten times". Examples of items 
in the scale are: Taken something from a store without paying for it? High scores indicate a high rate of delinquent behaviour. It has a Cronbach's Alpha value of 0.84 for the Nigeria Sample (Kumuyi et al., 2020).

\section{Results}

\subsection{Demographic Characteristics of Participants}

A total of 1006 adolescents, 483 males (48.0\%) and 523 females (52.0\%), participated in the study. The ages of the respondents were between $10-18$. According to school type, the distribution shows that 478 adolescents (47.5\%) were drawn from public secondary schools and 528 adolescents (52.5) from private secondary schools. Furthermore, 599 students (59.5\%) were from junior school 3, while 407 students (40.5\%) were from the senior schools 3 .

Table 1 summarizes the conduct disorder patterns using the frequency of delinquent behaviour scaling instrument (FDBSI). Patterns of dimensions according to the severity of conduct disorder (CD) reveals truancy with $15.4 \%$ (severe), Physical Aggression (PA) was next in with 10.2\% severity, Destructive Behaviour (DB) with $10.0 \%$ (severe), Theft (TH) with 9.01 (severe), vandalism level (V) with $6.80 \%$ and status offence with $6.30 \%$. Table 1 further reported a $59.1 \%$ prevalence of mild, $31.3 \%$ of moderate, and $9.6 \%$ severe total level of conduct disorder.

\subsection{Test of Hypotheses}

\subsubsection{Hypothesis 1}

Table 2 showed that parenting style had significant influence on conduct disorder $[\mathrm{F}(3,1002)=5.37, p<0.01]$. This table implies that the style of parenting adopted in adolescents' upbringing influences their conduct disorder experience. However, this result did not specify the difference in parenting style and the differences that led to the significant influence of conduct disorder. Therefore, the mean, standard deviation, and multiple comparison tests were conducted to determine the difference. The result is presented in Table 3.

Table 1. Patterns of conduct disorder among in-school adolescents.

\begin{tabular}{ccccc}
\hline \multirow{2}{*}{ Conduct Disorder } & Variables & \multicolumn{3}{c}{ Patterns (\%) } \\
\cline { 2 - 4 } & Vandalism & Mild & Moderate & Severe \\
\cline { 2 - 4 } Theft & 82.0 & 11.2 & 6.80 \\
Physical Aggression & 64.0 & 10.7 & 9.01 \\
Truancy & 58.7 & 25.8 & 10.2 \\
Destructive Behaviour & 80.8 & 9.20 & 15.4 \\
Status Offense & 86.0 & 7.70 & 10.0 \\
& & Patterns (\%) & \\
\cline { 2 - 4 } & & Mild & Moderate & Severe \\
\cline { 2 - 4 } Levels of Conduct Disorder (CD) & 59.1 & 31.3 & 9.6 \\
\hline
\end{tabular}


Table 2. One-way ANOVA showing the influence of parenting styles on conduct disorder.

\begin{tabular}{cccccc}
\hline Source & SS. & Df & MS & F & $p$ \\
\hline Parenting Style & 503.56 & 3 & 167.86 & 5.37 & $<0.01$ \\
Error & $31,327.67$ & 1002 & 31.27 & & \\
Total & $31,831.24$ & 1005 & & & \\
\hline
\end{tabular}

Table 3. Multiple comparison test (Scheffetest post hoc) showing differences of parenting styles on conduct disorder.

\begin{tabular}{lccccccc}
\hline Parenting Styles & N & Mean & SD & $\mathbf{1}$ & $\mathbf{2}$ & $\mathbf{3}$ & $\mathbf{4}$ \\
\hline 1) Authoritative & 507 & 24.65 & 5.07 & - & & & \\
2) Authoritarian & 69 & 26.38 & 5.56 & 0.33 & - & & \\
3) Permissive & 60 & 25.05 & 5.00 & 1.00 & 1.33 & - & \\
4) Negligent & 370 & 26.05 & 6.33 & $1.40^{*}$ & 1.72 & 0.40 & -
\end{tabular}

Note: ${ }^{*}$ indicated that the mean difference is significant at 0.05 level.

As summarized in Table 3, the authoritarian parenting style had the strongest influence on conduct disorder with a mean value of $26.38(\mathrm{SD}=5.56)$. This was followed by a negligent parenting style $(\mathrm{M}=26.05 ; \mathrm{SD}=6.33)$. Permissive parenting had a mean value of $25.05(\mathrm{SD}=5.00)$, while the least experienced in conduct disorder were adolescents whose parents utilized an authoritative parenting style $(\mathrm{M}=24.65 ; \mathrm{SD}=5.07)$.

The multiple comparison test revealed that the difference between authoritative parenting and authoritarian was not significant ( $\mathrm{MD}=0.33, p>0.05)$. Also, the mean difference between authoritative parenting style and permissive was not significant ( $\mathrm{md}=1.00, p>0.05)$. However, the authoritative parenting style had a significant mean difference compared to the negligent parenting style (MD $=1.40, p<0.05)$. The result in Table 3 also indicated that authoritarian parenting style had no significant difference compared with permissive parenting style ( $\mathrm{md}=1.33, p>0.05)$, and negligent parenting style $(\mathrm{MD}=1.72, p>0.05)$. Lastly, the permissive parenting style had no significant mean difference compared with the negligent parenting style ( $\mathrm{MD}=0.40, p>0.05$ ). This implied that the observed significant influence was attributed to the difference between authoritative parenting style and negligent parenting style.

Further analysis was conducted using the responsiveness and control categorization of parenting styles. This was meant to have a deeper understanding of the association between parenting styles and conduct disorder among adolescents. The factors were tested using multiple regression analysis and presented in Table 4.

The result in Table 4 indicated that responsiveness parenting style did not significantly predict conduct disorder $(\beta=0.08, p>0.05)$. However, control parenting style had a significant independent prediction score on conduct disorder. Table 4 further revealed that parenting style contributed $2 \%$ to the total variance of observed conduct disorder among the participants $\left(\mathrm{R}^{2}=0.02, p=0.01\right)$. This result concurs with our findings reported in Table 1 and thus implied that pa- 
renting style had a significant influence on conduct disorder among in-school adolescents.

\subsubsection{Hypothesis 2}

An independent t-test was carried out to determine the influence of parent's occupation on conduct disorder among Nigerian in-school adolescents. The t-test showed 492 formal occupations for fathers (Salary earners) and 514 informal occupations (Self-employed). For the mother occupation, there were 393 formal occupations and 613 informal occupations. The mean and standard deviation scores of the parents' occupation are shown in Table 5.

Table 5 shows that there was a statistically significant fathers' occupation [ $\mathrm{t}$ (1004) 2.71, $p=0.007]$ and mother occupation [t $(1004)=4.68 p=0.032]$ influence on conduct disorder among the respondents. Respondents who had fathers with formal occupation displayed higher mean \pm standard deviation scores $(25.80 \pm 5.633)$ than those whose fathers had informal occupation $(24.84 \pm$ 5.588). Respondents who had informal occupation mothers displayed higher mean \pm standard deviation scores $(25.00 \pm 5.771)$ than those whose mothers had formal occupation $(25.00 \pm 5.370)$. This study suggests that participants whose fathers had formal occupation displayed more conduct disorder than those whose fathers had an informal occupation. Finally, respondents whose mothers had formal occupations display more conduct disorder than those with mothers of informal occupations.

\subsubsection{Hypothesis 3}

A one-way ANOVA was carried out to compare the influence of the social-economic status on conduct disorder. The SES was categorized into three-level, namely Low SES, Middle SES, and high SES. The alpha level was set at 0.05 . The result of the analysis summarized in Table 6(a) and Table 6(b) indicates there is a significant influence of socioeconomic status on conduct dis$\operatorname{order}(\mathrm{F}(2,1003)=11.828, p<0.05)$.

Table 4. Multiple regression showing the prediction of conduct disorder by parenting styles.

\begin{tabular}{ccccccc}
\hline Variables & $\boldsymbol{\beta}$ & $\mathbf{T}$ & $\mathbf{R}$ & $\mathbf{R}^{2}$ & $\mathrm{Df}$ & $\mathbf{F}$ \\
\hline Responsiveness & 0.08 & 1.16 & & & & \\
Control & -0.23 & $-3.11^{\star *}$ & 0.16 & 0.02 & 2,1003 & $12.32^{\star *}$ \\
\hline
\end{tabular}

Note: ${ }^{* *} p<0.01, \mathrm{~N}=1006$.

Table 5. Independent samples t-test of the influence of parents' occupation on conduct disorder among in-school adolescents.

\begin{tabular}{ccccccc}
\hline Variables & & N & $\bar{X}$ & SD & t & $p$ \\
\hline Father & Formal & 492 & 25.80 & 5.633 & & 2.71 \\
Occupation & Informal & 514 & 24.84 & 5.588 & & 0.007 \\
Mother & Formal & 393 & 25.79 & 5.370 & & 0.032 \\
Occupation & Informal & 613 & 25.00 & 5.771 & & \\
\hline
\end{tabular}


Table 6. (a) Showing descriptive analysis of conduct disorder by socioeconomic status; (b) Summary table of one-way ANOVA showing the influence of socio-economic status on conduct disorder.

(a)

\begin{tabular}{cccc}
\hline Socio-Economic Status (SES) & N & Mean & Standard deviation \\
\hline Low SES & 81 & 24.0494 & 2.96606 \\
Middle SES & 605 & 24.8380 & 5.28119 \\
High SES & 320 & 26.5219 & 6.51688 \\
Total & 1006 & 25.3101 & 5.62787 \\
\hline
\end{tabular}

(b)

\begin{tabular}{cccccc}
\hline Groups & Sum of squares & df & Mean square & F & $\boldsymbol{p}$ \\
\hline Between Groups & 733.462 & 2 & 366.731 & & \\
Within Groups & $31,097.775$ & 1003 & 31.005 & 11.828 & $0.00^{*}$ \\
Total & $31,831.237$ & 1005 & & & \\
\hline
\end{tabular}

$\mathrm{F}(2,1003)=11.828, p<0.05$

A Post hoc multiple comparison using the Scheffe test showed that the mean score for High SES (Mean $=26.522, \mathrm{SD}=6.517$ ) was significantly different from low SES (Mean $=24.050, S D=2.966)$ and Middle SES (Mean $=24.839, \mathrm{SD}=$ 5.282). There was, however, no significant Mean \pm SD difference between Low SES and Middle SES. Taken together, this result showed that socioeconomic status has a significant influence on conduct disorder. Specifically, the result suggests that respondents with high socioeconomic status exhibit more conduct-related problems than children with middle and low SES, respectively.

\section{Discussions}

This present study shows a high prevalence of conduct disorder among in-school Nigerian adolescents. In a related Nigerian secondary school study, Diwe et al. (2016) reported that $69.7 \%$ of the respondents had committed at least one form of conduct behaviour or the other. Our research finding is also similar to that of Adekeye et al. (2015), where the mild severity category was $43.3 \%$, the moderate degree was $52.2 \%$, and the severe group was $4.4 \%$. Similarly, in a USA study, (Nock et al., 2006) reported a 9.5\% CD prevalence. A worldwide meta-analysis result reported a $3.2 \%$ prevalence of $\mathrm{CD}$ among children and adolescents of six to eighteen year (Canino et al., 2010). Previous studies by (Breslau et al., 2006) reported a 6.9\% prevalence of CD in Hispanic, 4.9\% in Black and 5.0\% in White children and adolescents.

The findings of our study affirm significant parenting style influence on conduct disorder. This supports previous research (Verzello, 2010; Berger, 2011; Hockenbury, 2013) on the link between parenting styles and CD. Literature shows that the authoritative parenting style is associated with positive adolescent outcomes (Hockenbury, 2013) and is regarded as the most effective and benefi- 
cial parenting style. Adolescents with authoritative parents are less prone to externalizing behaviour and are significantly less likely to engage in drug use than individuals with uninvolved parents (Andal et al., 2016; Park et al., 2010). On the other hand, children raised under the authoritarian style of parenting are introverted, rule-abiding, conformist, and often struggle with depression, anxiety, and self-blame (Berger, 2011).

Additionally, children who become resentful about being raised in an authoritarian environment often become rebellious in adolescence and have escapist behaviour such as substance abuse and suicidal ideations (Berger, 2011). According to Baumrind (1991), children raised under the indulgent-permissive parenting style are often immature, lack impulse control, and irresponsible. In adolescence, they can become more impulsive and engage in misconduct such as drug use (Baumrind, 1991; Leschied et al., 2008). Finally, children raised under uninvolved parenting homes have to fend for themselves, have reduced dependence on parents, and earlier independence (Patterson \& Fisher, 2002). They also lack attachment to their families and, as adolescents, are often emotionally withdrawn (O'Connor et al., 2013), often manifesting in CD.

Furthermore, our study found a significant influence of socioeconomic status on the manifestation of conduct disorder among Nigerian adolescents. This finding supports D'Onofrio et al. (2009), affirming a causal association between family income and conduct disorder. Also, family income is equally reported as a critical risk factor for the development of early-onset $\mathrm{CD}$. There are, however, contradicting result findings reported in the literature on the level of influence of family income on CD. For instance, Legleye et al. (2010) found no statistically significant family income influence between the low and the high socioeconomic status (SES). According to them, adolescents from both high and low-SES families engage in delinquencies. On the flip side, children from low income have been reported as having severe conduct issues (Proctor et al., 1992; Farrington, 1990; Loeber et al., 2000). In a recent finding, Patel et al. (2018) reported that children from median income families manifested higher psychiatric hospitalization resulting from conduct disorder.

Our study also found that the father's occupation had a significant influence on $\mathrm{CD}$ among Nigerian adolescents. In a study that compared mothers who work versus those who do not, Heinrich (2014) affirmed that employment form influences parenting in opposing ways. On the positive side, it provides the financial means to meet parenting obligations, while the disadvantage is that it reduces the time available to spend with family. Stressful job conditions associated with working a nonstandard schedule may, in turn, lead to less positive family dynamics, including reduced time spent with children and lower parental knowledge of children's whereabouts. Analyses on children's developmental stage suggest that the number of years parents spend on formal occupation types at various stages of childhood matter for adolescent outcomes depending on the development stage when that work occurred (Eccles, 1999). In particular, the 
middle-childhood years mark a time of significant changes related to school transitions. These developmental advances establish children's sense of identity and relationship development with parents and peers (Eccles, 1999). These years serve as a foundation for later development, and experiences can have lasting effects during these periods.

According to Stansfeld, Rasul, Head and Singleton (2009), occupations can be classified as low risk and others as high risk as a result of their influence on mental health. The perceived risk level involved in a job often translates to stressors. In this sense, higher parenting stress, resulting from the nature of the occupation, relates to an increase in family conflict for both men and women (Gallavan \& Newman, 2013). For instance mothers, negative experiences at work have shown significant increase in negative parenting, decreased enjoyable interactions and sensitivity, and increased negative interactions with their children (Costigan, Cox, \& Cauce, 2003), resulting in emotional burden on both the parent and the child (StGeorge \& Fletcher, 2011), and a higher frequency of internalizing and externalizing behaviors in children (Downey \& Coyne, 1990).

Furthermore, research suggested that parents should know their children's whereabouts and daily life at a younger age against when they are older (Crouter \& Head, 2002; Young et al., 2019). The implication is that engaging in a formal occupation has the propensity of reducing parental knowledge of children's whereabouts and their daily life activities. This gap may limit the involvement of parents in child's life, resulting in child's emotional detachment and parents minimal response to the child's needs (Young et al., 2019; Samuels, 2011; Lee et al., 2006), a risk factor to CD (Simons \& Conger, 2007; Hoeve, Dubas, Gerris, van der Laan, \& Smeenk, 2011).

\section{Conclusion and Recommendation}

Based on this present study's findings, the authors conclude a high conduct disorder rate among in-school Nigerian adolescents. For there to be a decrease in conduct disorder among adolescents, there must be attention to parenting. This research has provided a clear and reliable path to increase positive qualities for positive outcomes. Authoritative parenting is the most effective parenting style, with permissive parenting coming in second. The permissive, authoritarian, and uninvolved parenting styles were ineffective in encouraging morality as they encouraged antisocial behaviour, poor psychological health, and poor coping skills.

Several other conclusions can be drawn from this study. First is that parents' occupation is a significant determinant of conduct disorder. Secondly, formal jobs pose a higher risk than informal occupations in determining conduct disorder among adolescents among the types of occupations. Thirdly, socioeconomic factors are determinants of conduct disorder, and lastly, those with higher socioeconomic factors displayed more conduct related than the lower socioeconomic class. The implication is that parents should not view their occupations only from their perspective, that is, of achieving career fulfilment and economic 
empowerment; instead, they should realize that their occupation, career-driven nature, and pursuit for wealth can significantly influence their children's mental health if there is no proper balance.

\section{Informed Consent}

With regards to international standards participants, written consent was obtained for this study.

\section{Ethical Approval}

The research intention and procedure were examined and approved by the Internal Research Ethics Committee's (IREC) of Redeemer's University, Ede, Osun State Nigeria, and the Oyo State Ministry of Education, ethical research committee. The research was carried out following the ethical standards laid down in the 1964 declaration of Helsinki.

\section{Conflicts of Interest}

The authors declare no conflicts of interest regarding the publication of this paper.

\section{References}

Adekeye, S. O., Gesinde, A. M., Alao, A. A., Adejumo, G. O., \& Adekeye, O. A. (2015). Differential Effect of Behavioural Strategies on the Management of Conduct Disorder among Adolescents in Correctional Centres in Lagos State, Nigeria. International Journal of Psychology and Counselling, 7, 63-68. https://doi.org/10.5897/IJPC2015.0304

Akinnawo, E. O. Akpunne, B. C., \& Olajide, O. A. (2019). Parenting Style, Emotional Intelligence and Psychological Health of Nigerian Children. Asian Journal of Pediatric Research, 2, 1-11. https://doi.org/10.9734/ajpr/2019/v2i230100

American Psychiatric Association (APA) (2013). Diagnostic and Statistical Manual for Mental Disorders (5th ed., DSM-5). Washington DC: American Psychiatric Association. https://doi.org/10.1176/appi.books.9780890425596

American Psychological Association (APA) (2015). Professional Practice Guidelines: Guidance for Developers and Users. American Psychologist, 70, 823-831.

https://doi.org/10.1037/a0039644

Andal, F. A., Amante, A., Miyagawa, A. H. et al. (2016). Single Parenting Style as a Predictor of Juvenile Delinquency on Selected Cities of Cavite. International Journal of Psychology and Counselling, 6, 15-31.

Baker, K. (2012). Conduct Disorders in Children and Adolescents. Paediatrics and Child Health, 23, 24-29. https://doi.org/10.1016/j.paed.2012.09.007

Bartlett, J. E., Kotrlik, J. W., \& Higgins, C. C. (2001). Organizational Research: Determining Appropriate Sample Size in Survey Research. Learning and Performance Journal, 19, 43-50.

Baumrind, D. (1991). The Influence of Parenting Style on Adolescent Competence and Substance Use. Journal of Early Adolescence, 11, 56-95.

https://doi.org/10.1177/0272431691111004 
Berger, K. S. (2011). The Developing Person through the Life Span. Worth Publishers. New York, USA.

Bowlby, J. (1969). Attachment and Loss (OKS Print). New York: Basic Books.

Bowlby, J. (1982). Attachment and Loss: Retrospect and Prospect. American Journal of Orthopsychiatry, 52, 664-678. https://doi.org/10.1111/j.1939-0025.1982.tb01456.x

Breslau, J., Aguilar-Gaxiola, S., Kendler, K. S., Su, M., Williams, D., \& Kessler, R. C. (2006). Specifying Race-Ethnic Differences in Risk for a Psychiatric Disorder in a USA National Sample. Psychological Medicine, 36, 57-68. https://doi.org/10.1017/S0033291705006161

Buitelaar, J. K., Kirsten, C., Smeets, K. C., Herpers, P., Scheepers, F., Glennon, J., \& Rommelse, N. J. N. (2012). Conduct Disorders. European Child \& Adolescent Psychiatry, 22, 49-54. https://doi.org/10.1007/s00787-012-0361-y

Busari, A. O., \& Adejumobi (2012). Cognitive Behaviour Therapy in the Management of Juvenile Delinquency. International Conference on Sustainable Development in Africa, R. S. Amegashe Auditorium, University of Ghana, Legon, Accra, 25-27 July 2012.

Calado, F., Alexandre, J., \& Griffiths, M. D. (2017). Prevalence of Adolescent Problem Gambling: A Systematic Review of Recent Research. Journal of Gambling Studies, 33, 397-424. https://doi.org/10.1007/s10899-016-9627-5

Canino, G., Polanczyk, G., Bauermeister, J. J., Rohde, L. A., \& Frick, P. J. (2010). Does the Prevalence of CD and ODD Vary across Cultures? Social Psychiatry and Psychiatric Epidemiology, 45, 695-704. https://doi.org/10.1007/s00127-010-0242-y

Chen, E. (2004). Why Socioeconomic Status Affects the Health of Children: A Psychosocial Perspective. Current Directions in Psychological Science, 13, 112-115. https://doi.org/10.1111/j.0963-7214.2004.00286.x

Chen, E., \& Paterson, L. Q. (2006). Neighborhood, Family, and Subjective Socioeconomic Status: How Do They Relate to Adolescent Health? Health Psychology, 25, 704-714. https://doi.org/10.1037/0278-6133.25.6.704

Chiedu, A. A., Solaja, O. M., \& Olawunmi, S. D. (2015). Perception on the Trend and Patterns of Youth Criminality in Ibadan South-Western, Nigeria. African Journal for the Psychological Study of Social Issues, 18, 72-81

Costigan, C. L., Cox, M. J., \& Cauce, A. (2003). Work-Parenting Linkages among Dual-Earner Couples at the Transition to Parenthood. Journal of Family Psychology, 17, 397-408. https://doi.org/10.1037/0893-3200.17.3.397

Cronin, S., Becher, E. H., Christians, K. S., Maher, M., \& Dibb, S. (2015). Parents and Stress: Understanding Experiences, Context and Responses. St. Paul, MN: University of Minnesota Extension, Children, Youth and Family Consortium. https://conservancy.umn.edu/bitstream/handle/11299/172384/parental-stress-2015.pdf ?sequence $=1$ \&isAllowed $=y$

Crosswhite, J. M., \& Kerpelman, J. (2009). Coercion Theory, Self-Control, and Social Information Processing: Understanding Potential Mediators for How Parents Influence Deviant Behaviors. Deviant Behaviour, 30, 611-646. https://doi.org/10.1080/01639620802589806

Crouter, A. C., \& Head, M. R. (2002). Parental Monitoring and Knowledge of Children. In M. H. Bornstein (Ed.), Handbook of Parenting (pp. 461-483). Mahwah, NJ: Erlbaum.

D’Onofrio, B. M., Goodnight, J. A., Van Hulle, C. A., Rodgers, J. L., Rathouz, P. J., Waldman, I. D., \& Lahey, B. B. (2009). A Quasi-Experimental Analysis of the Association between Family Income and Offspring Conducts Problems. Journal of Abnormal 
Child Psychology, 37, 415-429. https://doi.org/10.1007/s10802-008-9280-2

Dahlberg, L. L., Toal, S. B., Swahn, M., \& Behrens, C. B. (2005). Violence-Related Attitudes, Behaviors, and Influences among Youths: A Compendium of Assessment Tools (2nd ed.). Atlanta, GA: Centers for Disease Control and Prevention, National Center for Injury Prevention and Control.

https://www.cdc.gov/violenceprevention/pdf/yv compendium.pdf https://doi.org/10.1037/e554402012-001

DeKlyen, M., \& Speltz, M. (2000). Attachment and Conduct Disorder. In J. Hill, \& B. Maughan (Eds.), Conduct Disorders in Childhood and Adolescence. Cambridge Child and Adolescent Psychiatry (pp. 320-345). Cambridge: Cambridge University Press. https://doi.org/10.1017/CBO9780511543852.013

Dekovic, M., \& Janssens, J. M. (2003). Parental Predictors of Antisocial Behaviour in Adolescence. Family Process, 42, 223-235. https://doi.org/10.1111/j.1545-5300.2003.42203.x

Diwe, K., Aguocha, C., Duru, C., Uwakwe, K., Merenu, A., \& Nwefoh, E. (2016). Gender Differences in Prevalence and Pattern of Conduct Disorder among Adolescent Secondary School Students in South East Nigeria. Asian Journal of Social Sciences \& Humanities, 5, 49-58.

Dodge, K. A., Greenberg, M. T., \& Malone, P. S. (2008). Testing an Idealized Dynamic Cascade Model of the Development of Serious Violence in Adolescence. Child Development, 79, 1907-1927. https://doi.org/10.1111/j.1467-8624.2008.01233.x

Downey, G., \& Coyne, J. C. (1990). Children of Depressed Parents: An Integrative Review. Psychological Bulletin, 108, 50-76. https://doi.org/10.1037/0033-2909.108.1.50

Eccles, J. S. (1999). The Development of Children Ages 6 to 14. The Future of Children, 9, 30-44. https://doi.org/10.2307/1602703

Fairchild, G., Hawes, D. J., Frick, P. J., Copeland, W. E., Odgers, C. L., Franke, B., Freitag, C. M., \& De Brito, S. A. (2019). Conduct Disorder. Nature Reviews Disease Primers, 5, 43. https://doi.org/10.1038/s41572-019-0095-y

Farmer, R. F., Gau, J. M., Seeley, J. R., Kosty, D. B., Sher, K. J., \& Lewinsohn, P. M. (2016). Internalizing and Externalizing Disorders as Predictors of Alcohol Use Disorder Onset during Three Developmental Periods. Drug and Alcohol Dependence, 164, 38-46. https://doi.org/10.1016/j.drugalcdep.2016.04.021

Farrington, D. P. (1990). Implications of Criminal Career Research for the Prevention of Offending. Journal of Adolescence, 13, 93-113. https://doi.org/10.1016/0140-1971(90)90001-N

Feist, J., Feist, G. J., \& Roberts, T. (2013). Theories of Personality. Dubuque, IA: McGraw-Hill Education.

Frank-Briggs, A., \& Alikor, E. A. (2008). Conduct Disorder among Children in an Urban School in Nigeria. The Nigerian Health Journal, 8, 44-47.

Gafoor, A. K., \& Kurukkan, A. (2014). Construction and Validation of Scale of Parenting Style. Guru Journal of Behavioral and Social Sciences, 2, 315-323.

Gallavan, D. B., \& Newman, J. L. (2013). Predictors of Burnout among Correctional Mental Health Professionals. Psychological Services, 10, 115-122. https://doi.org/10.1037/a0031341

Gavazzi, S. M. (2006). Gender, Ethnicity, and the Family Environment: Contributions to Assessment Efforts within the Realm of Juvenile Justice. Family Relations, 55, 190-199. https://doi.org/10.1111/j.1741-3729.2006.00369.x

Gureje, O., Lasebikan, V. O., Kola, L., \& Makanjuola, V. A. (2006). Lifetime and 
12-Month Prevalence of Mental Disorders in the Nigerian Survey of Mental Health and Well-Being. British Journal of Psychiatry, 188, 465-471. https://doi.org/10.1192/bjp.188.5.465

Heinrich, C. J. (2014). Parents' Employment and Children's Wellbeing. The Future of Children, 24, 121-146. https://doi.org/10.1353/foc.2014.0000

Hockenbury, S. (2013). Juveniles in Residential Placement, 2010. Juvenile Offenders and Victims: National Report Series Bulletin, US Department of Justice Office, Programs Office of Juvenile Justice and Delinquency Prevention.

Hoeve, M., Dubas, J. S., Gerris, J. R. M., Van der Laan, P. H., \& Smeenk, W. H. (2011). Maternal and Paternal Parenting Styles: Unique and Combined Links to Adolescent and Early Adult Delinquency. Journal of Adolescence, 34, 813-827. https://doi.org/10.1016/j.adolescence.2011.02.004

Kilgore, K., Snyder, J., \& Lentz, C. (2000). The Contribution of Parental Discipline, Parental Monitoring, and School Risk to Early-Onset Conduct Problems in African American Boys and Girls. Developmental Psychology, 36, 835-845. https://doi.org/10.1037/0012-1649.36.6.835

Kumuyi, D. O., Akinnawo, O. E., \& Akintola, A. (2020). Validation of the Frequency of Delinquent Behaviour Scaling Instrument on Nigerian In-School Adolescents. International Journal of Recent Advances in Multidisciplinary Research, 7.

Lee, S. M., Daniels, M. H., \& Kissinger, D. B. (2006). Parenting Influences on Adolescent Adjustment: Parenting Styles versus Parenting Practices. The Family Journal, 14, 253-259. https://doi.org/10.1177/1066480706287654

Legleye, S., Obradovic, I., Janssen, E., Spilka, S., Le Nézet, O., \& Beck, F. (2010). Influences of Cannabis Use Trajectories, School Failure and Family Background on School Dropout at 17 in France. European Journal of Public Health, 20, 157-163. https://doi.org/10.1093/eurpub/ckp148

Leschied, A., Chiodo, D., Nowicki, E., \& Rodger, S. (2008). Childhood Predictors of Adult Criminality: A Meta-Analysis Drawn from the Prospective Longitudinal Literature. Canadian Journal of Criminology and Criminal Justice, 50, 435-467. https://doi.org/10.3138/cjccj.50.4.435

Lewis, G. J., Asbury, K., \& Plomin, R. (2017). Externalizing Problems in Childhood and Adolescence Predict Subsequent Educational Achievement but for Different Genetic and Environmental Reasons. Journal of Child Psychology and Psychiatry, 58, 292-304. https://doi.org/10.1111/jcpp.12655

Loeber, R., Burke, J. D., Lahey, B. B., Winters, A., \& Zera, M. (2000). Oppositional Defiant and Conduct Disorder: A Review of the Past 10 Years, Part I. Journal of the American Academy of Child and Adolescent Psychiatry, 39, 1468-1484. https://doi.org/10.1097/00004583-200012000-00007

Maccoby E. E., \& Martin, J. A. (1983). Socialization in the Context of the Family: Parent-Child Interaction. In Handbook of Child Psychology. New York : Wiley.

Mikulincer, M., \& Shaver, P. R. (2012). An Attachment Perspective on Psychopathology. World Psychiatry, 11, 11-15. https://doi.org/10.1016/j.wpsyc.2012.01.003

Nock, M. K., Kazdin, A. E., Hiripi, E., \& Kessler, R. C. (2006). Prevalence, Subtypes, and Correlates of DSM-IV Conduct Disorder in the National Comorbidity Survey Replication. Psychological Medicine, 36, 699-710. https://doi.org/10.1017/S0033291706007082

O’Connor, T., Matias, C., Futh, A., Tantam, G., \& Scott, S. (2013). Social Learning Theory Parenting Intervention Promotes Attachment-Based Caregiving in Young Children: Randomized Clinical Trial. Journal of Clinical Child and Adolescent Psychology, 42, 
358-370. https://doi.org/10.1080/15374416.2012.723262

OECD (2008). 2008 OECD Study Household Survey on Environmental Attitudes and Behavior: Data Corroboration. https://www.oecd.org/env/consumption-innovation/44101274.pdf

Ojuope, A. V., \& Ekunudayo, O. O. (2020). Conduct Disorder and Its Relationship with Socio-Demographics Factors among Secondary School Adolescents in Ondo State, Nigeria. American Journal of Applied Psychology, 9, 60-65.

https://doi.org/10.11648/j.ajap.20200903.12

Park, Y. S., Kim, B. S. K., Chiang, J., \& Ju, C. M. (2010). Acculturation, Enculturation, Parental Adherence to Asian Cultural Values, Parenting Styles and Family Conflict among Asian American College Student. Asian American Journal of Psychology, 1, 67-79. https://doi.org/10.1037/a0018961

Patel, R. S., Amaravadi, N., Bhullar, H., Lekireddy, J., \& Win, H. (2018). Understanding the Demographic Predictors and Associated Comorbidities in Children Hospitalized with Conduct Disorder. Behavioural Sciences (Basel, Switzerland), 8, 80. https://doi.org/10.3390/bs8090080

Patterson, G. R., \& Fisher, P. A. (2002). Recent Developments in Our Understanding of Parenting: Bidirectional Effects, Causal Models, and the Search for Parsimony. In M. Bornstein (Ed.), Handbook of Parenting: Practical and Applied Parenting (2nd ed., Vol. 5, pp. 59-88). Mahwah, NJ: Erlbaum.

Proctor, E. K., Vosler, N. R., \& Murty, S. (1992). Child Demographics and DSM Diagnosis: A Multi-Axis Study. Child Psychiatry \& Human Development, 22, 165-183. https://doi.org/10.1007/BF00705890

Propper, C., \& Rigg, J. (2007). Socioeconomic Status and Child Behaviour: Evidence from a Contemporary UK Cohort. CASEpapers (125). London: Centre for Analysis of Social Exclusion, London School of Economics and Political Science.

http://eprints.lse.ac.uk/6210/1/Socio-Economic Status and Child Behaviour Evidenc e from a contemporary UK cohort.pdf

Saheed, A. A. (2019). Statistical Analysis of Insecurity and Criminal Cases in Ibadan, Oyo State Nigeria. International Journal of Research and Scientific Innovation (IJRSI), 6, $10-18$.

Samuels, J. E. (2011). An Update on the "Cycle of Violence" (pp. 1-8). National Institute of Justice: Research in Brief.

Scott, S. (2007). Conduct Disorder in Children. BMJ, 334, 646.

http://www.bmj.com/cgi/content/full/334/7595/646

https://doi.org/10.1136/bmj.39161.370498.BE

Simons, L. G., \& Conger, R. D. (2007). Linking Mother-Father Differences in Parenting to a Typology of Family Parenting Styles and Adolescent Outcomes. Journal of Family Issues, 28, 212-241. https://doi.org/10.1177/0192513X06294593

Simons, R. L., Chao, W., Conger, R. D., \& Elder, G. H. (2001). Quality of Parenting as Mediator of the Effect of Childhood Defiance on Adolescent Friendship Choices and Delinquency: A Growth Curve Analysis. Journal of Marriage and Family, 63, 63-79. https://doi.org/10.1111/j.1741-3737.2001.00063.x

Smith, C. A., \& Farrington, D. P. (2004). Continuities in Antisocial Behaviour and Parenting across Three Generations. Journal of Child Psychology and Psychiatry, 45, 230-247. https://doi.org/10.1111/j.1469-7610.2004.00216.x

Stansfeld, S. A., Rasul, F. R., Head, J., \& Singleton, N. (2009). Occupation and Mental Health in a National UK Survey. Social Psychiatry \& Psychiatric Epidemiology, 46, 101-110. https://doi.org/10.1007/s00127-009-0173-7 
StGeorge, J. M., \& Fletcher, R. J. (2012). Time for Work, Commuting, and Parenting? Commuting Parents' Involvement with Their Children. Community, Work \& Family, 15, 273-291. https://doi.org/10.1080/13668803.2012.662802

Tremblay, R. E. (2010). Developmental Origins of Disruptive Behaviour Problems: The "Original Sin" Hypothesis, Epigenetics and Their Consequences for Prevention. Journal of Child Psychology and Psychiatry, 51, 341-367.

https://doi.org/10.1111/j.1469-7610.2010.02211.x

Van der Ende, J., Verhulst, F. C., \& Tiemeier, H. (2016). The Bidirectional Pathways between Internalizing and Externalizing Problems and Academic Performance from 6 to 18 Years. Development and Psychopathology, 28, 855-867. https://doi.org/10.1017/S0954579416000353

Verzello, A. (2010). Teens and Alcohol Study: Parenting Style Can Prevent Binge Drinking. Brigham Young University News.

https://news.byu.edu/news/teens-and-alcohol-study-parenting-style-can-prevent-binge -drinking

World Health Organization (WHO) (2016). Maternal, Newborn, Child and Adolescent Health: Adolescent Development.

https://www.who.int/health-topics/adolescent-health/\#tab=tab 1

Yap, M. B. H., Fowler, M., Reavley, N., \& Jorm, A. F. (2015). Parenting Strategies for Reducing the Risk of Childhood Depression and Anxiety Disorders: A Delphi Consensus Study. Journal of Affective Disorders, 183, 330-338. https://doi.org/10.1016/j.jad.2015.05.031

Young, E. S., Simpson, J. A., Griskevicius, V., Huelsnitz, C. O., \& Fleck, C. (2019). Childhood Attachment and Adult Personality: A Life History Perspective. Self and Identity, 18, 22-38. https://doi.org/10.1080/15298868.2017.1353540 